\title{
REGIONAL APPROACH TO PRESERVATION OF FOOD RELATED BIODIVERSITY
}

\author{
D. Dimitrova $^{1 *}$, T. Ivanova ${ }^{1}$, M. Chervenkov ${ }^{2}$, Y. Bosseva $^{1}$, M. Rumiz ${ }^{3}$ \\ ${ }^{1}$ Department of Plant and Fungal Diversity and Resources, Institute of Biodiversity and Ecosystem \\ Research, Bulgarian Academy of Sciences, Sofia, Bulgaria \\ ${ }^{2}$ Institute of Biology and Immunology of Reproduction, Bulgarian Academy of Sciences, Sofia, \\ Bulgaria \\ ${ }^{3}$ Slow Food International, Bra, Italy
}

\begin{abstract}
PURPOSE: Strategy and major results of the Environmentally Sustainable Socio-Economic Development of Rural Areas (ESSEDRA) project are presented. The project relies on collaborative network involving 8 Balkan countries (including Turkey) with leading partnership of Slow Food International and European Forum on Nature Conservation and Pastoralism (UK). The overall purpose is to involve local communities in protecting the environment, especially in safeguarding agrobiodiversity and related traditional knowledge, to mitigate the impact of climate change and to secure the sustainable development of rural areas. METHODS: The activities aim at advocating the role of small-scale farmers in biodiversity protection, promoting targeted models and actions to preserve biodiversity, and exchanging best practices and knowledge at a multiregional level. RESULTS: Outcomes from the first stage of the project are presented and in the overall Balkan agriculture tendencies is discussed focusing on the current problems in Bulgarian small-scale agriculture. CONCLUSIONS: Steps for common approach for community-based regional development, biodiversity conservation, policy influencing, advocacy and capacity building in the field, collaboration between stakeholders are proposed.
\end{abstract}

Key words: plant varieties, animal breeds, agrobiodiversity, local communities

\section{INTRODUCTION}

The balance between the growing food demand and nature preservation is an on-going global issue that could be hardly solved fast and with single-side decisions (1-3). Land use activities have threatened and degraded ecosystems and their functioning worldwide (4). European agriculture is simultaneously suffering of increasing intensification and land abandonment in some rural areas. Both trends have a negative impact on farmland biodiversity and the livelihood of local communities $(5,6)$. Current European policies strive to mingle economic growth and sustainable biodiversity usage. However the effects are yet to be discussed (7-10).

Utilized agricultural areas in Bulgaria

\footnotetext{
* Correspondence to: Dessislava Dimitrova, Department of Plant and Fungal Diversity and Resources, Institute of Biodiversity and Ecosystem Research, Bulgarian Academy of Sciences, 23, Acad. G. Bonchev Str., 1113, Sofia, Bulgaria, email:dessidim3010@gmail.com
}

comprise ca. $46 \%$ of the country's territory, placing Bulgaria among the EU countries with highest percentage of agricultural land (11). The structure of agriculture in Bulgaria is bipolar. Farm holdings with less than 5 ha of used agricultural land constitute $91 \%$ of all holdings but they possess $5.2 \%$ of the whole cultivated land and produce $8.7 \%$ of the standard production volume. There is a tendency towards an increase of the average farm size. However, a parallel trend is the concentration of cultivated land in large holdings (with more than 100 ha of agricultural land) and in 2010 these large holdings possess $82.4 \%$ of the whole agricultural land. The number of farms with land between 5 and 50 ha rapidly increases but the land that they manage remains small $-7.9 \%$. This trend persists over the first programming period and in $201485 \%$ of the agricultural land is owned by large establishments which represent only $4 \%$ of all farms (12). Parallel to these trends are the continuous depopulation of the Bulgarian rural areas, accompanied by aging of 
DIMITROVA D., et al.

the rural population and high unemployment rates (13).

The above presented situation in Bulgarian rural areas poses a serious threat to traditional food products, local plant varieties and breeds. They fall victims not only to the unfavourable social-economic changes, globalization and industrial agriculture, but also to the rigid hygiene rules that have been imposed to Bulgarian farmers in the course of the EU accession. The EU regulations have been implemented in Bulgaria without economic analysis of their impact on Bulgarian farmers. The flexibility provisions for the implementation of the EU hygiene package have not been implemented in the national legal framework as a result of which the traditional farming and artisan food production have been doomed to extinction.

The new CAP (2014-2020) is calling for a greener and better balanced rural development in Europe where farmers are the central driving force. Engaging rural stakeholders and communities is needed to achieve advancement in the processes of rural development. Local mobilisation, community initiatives, but also building honest partnerships between stakeholders and governments are the prerequisites for success. It has to come from the communities themselves, but it has to be supported by decision makers and policies. It is a two-way process between rural communities and decision makers who create policies that requires a lot of effort and the right tools to make it possible.

Therefore, in 2013 the project ESSEDRA (Environmentally Sustainable Socio-Economic Development of Rural Areas) was launched (www.essedra.com). A major achievement of this project is the inventory of food-related biodiversity in the Balkans and Turkey. In the present paper we focus on the findings in Bulgaria and discuss their importance for the preservation of Bulgarian genetic resources and their potential for sustainable development of small businesses in rural areas. We discuss also the potential of the agro-ecological measures to support these efforts that are envisaged by the EC regulation № 1305/2013 and are included in the Bulgarian RDP (20142020).

\section{MATERIAL AND METHODS}

The study has been conducted since December 2012 in rural areas of Bulgaria. The areas of inventory were preselected based on previous experience of the experts and available literature; existing local communities and previous knowledge on local food biodiversity and food communities; areas with preserved nature and local livelihoods; developed rural tourism and small-scale and artisan food production. The core of the questionnaire consists of the following types of information:

- name of the product, including in the local dialect;

- description of the product;

- history of the product origin and primary area of production;

- approximate quantities of production;

- commercialization of the product (access to market or home consumption);

- existing and potential threats.

Statistical data on Bulgarian agricultural sector were obtained from the National yearbooks of the National Statistical Institute of Republic of Bulgaria, the reports of the Agrostatistics department in the Ministry of Agriculture and Food (MAF), Bulgarian official variety lists and Information system EFABIS of the Executive Agency for Selection and Reproduction in Animal Breeding (EASRAB) (14-21).

\section{RESULTS AND DISCUSSION}

\section{Livestock breeding}

Since 1980 the count of farm animals in Bulgaria has been significantly reduced. This trend is very tangible after 1990, when the transition from centrally planned to market economy system started. This was clearly demonstrated in the case with the main productive livestock. The reduction of the number of animals from 1990 to 2014 is very large - 5.94 times for sheep, 2.64 times for cattle and 7.58 times for pigs (Figure 1). A variety of reasons for this drop down can be mentioned. The collective farms were privatized and the land and animals were restituted. Many of the new land owners (or their heirs) had neither the knowledge, nor the desire to practice livestock breeding or agriculture. This process lead to decrease of the number of farm animals, along with the amount of land used for forage production. The decrease of the state support to animal husbandry in the pre-accession period and the import of cheaper agricultural goods additionally have worsened the situation in Bulgaria. The mass privatization of the factories for processing wool and leather, cheese dairies, slaughter houses and meat processing facilities also have caused deterioration of the sector. The result is that the international markets for animal products originating from Bulgaria have been lost. Last but not least, a considerable decline has been observed in the activities of the artificial 
insemination centres, the livestock breeding and agricultural institutes in the country. As a result a vast majority of animals were slaughtered or sold abroad and the import of animal products increased in order to satisfy the needs of the Bulgarian population. This trend is illustrated by the example with the consumption of red meat (Figure 2).

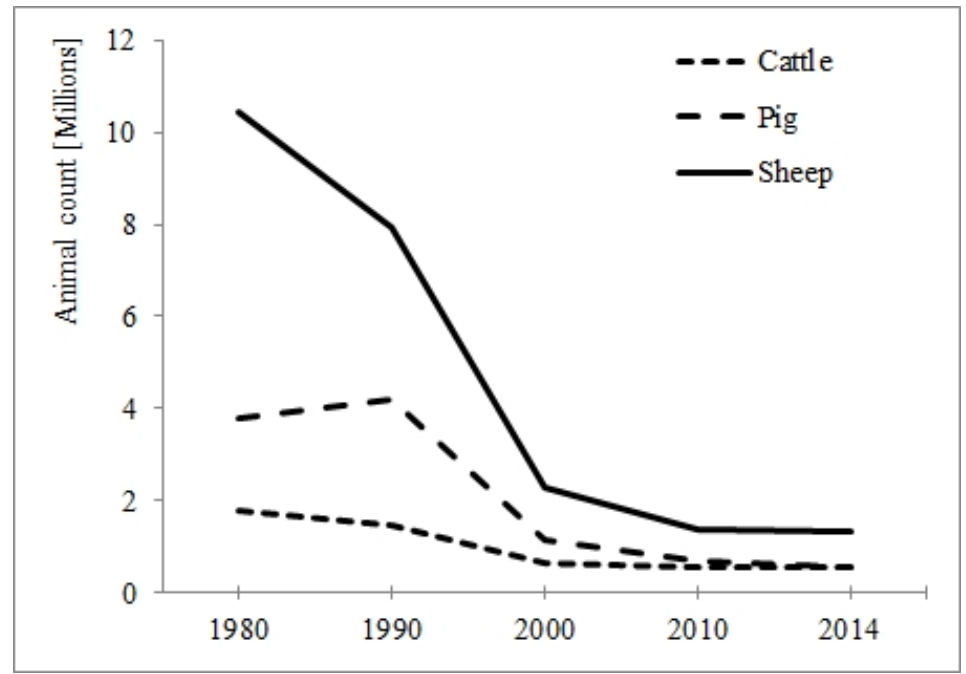

Figure 1. Main productive farm animals count in the period 1980-2014 (source: National Statistical Institute).

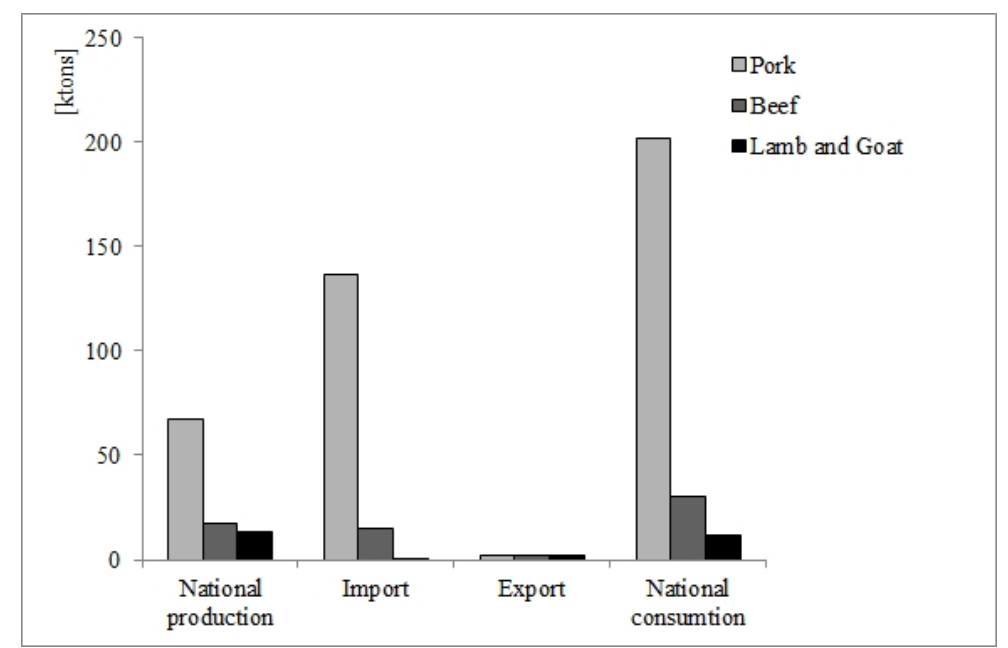

Figure 2. National production, trade and consumption of red meat in 2014 (soure: MAF Agrostatistics).

In 2014 a total of 98,232 tons (in carcass weight) of red meat was produced $-63 \%$ of the meat was obtained in registered slaughter houses and $37 \%$ in the farms of the country (20). The red meat from the private farms is mainly for personal use and has no serious market share. The figure shows that pork is the most used red meat for human consumption, followed by beef and less lamb and goat. When beef and especially pork meat are concerned a pronounced disproportion between national production and consumption is observed. The insufficient local production of main red meats requires a great amount of import to satisfy the needs of the Bulgarian consumers. For instance, the imported pork meat is two times bigger than the domestic production. The overall use of lamb and goat meat in the country gives way to other types of meat, mostly due to their higher prices and the significant reduction in local production.
As a result of the economic changes in the last 25 years, the size of the populations of the traditional and indigenous animal breeds has been substantially reduced. From the officially listed 45 Bulgarian autochthonous breeds 30 are under the control of breeding associations (22). There are on-going efforts for the creation of new breeding associations, new animals are categorized and new farmers get involved in the breeding of autochthonous animals (23). Recognizing the importance of indigenous breeds as precious genetic resource a special agro-ecological measure within SAPARD and Rural Development Program (2007 - 2013) has provided financial support for farmers who rear such animals. During the first programming period of RDP under the Measure 214 "Agro-ecological payments" ("Preservation of endangered local breeds") financial support was provided for 4 cattle breeds, 1 buffalo breed, 3 goat breeds, 4 horse 
breeds, 2 breeds of pigs and 20 sheep breeds. Unfortunately some breeds were included only in 2013 which prevented their support under the previous RDP (24). In 2014 the implementation of this measure resulted in the increase of the population size of most of the subsidized breeds (23 out of 34) compared to 2009. According to EFABIS information system best results were achieved in the following breeds: Rhodope Shorthorn Cattle from 361 (2009) to 1624 (2014); Bulgarian Gray Cattle - from 1156 (2009) to 2990 (2014) ); Kalofer Long-Haired Goat - from 727 (2011) to 2404 (2014); Local Long-Haired Goat from 515 (2013) to 2025 (2014); Karakachan Horse - from 264 (2009) to 2800 (2014); Patch-faced Maritza Sheep - from 1887 (2009) to 4065 (2014); .Duben Sheep - from 3532 (2009) to 7077 (2014); Cooper-Red Shumen Sheep - from 3436 (2009) to 6823 (2014); Balkan mountains/Stara Planina Tzygay - from 1074 (2009) to 8334 (2014). Unfortunately, in some breeds such as East Bulgarian Horse, Danube White Pig, Koprivshtitsa Sheep, Breznik Sheep, North-East Bulgarian Merino Sheep, there is even a decline, which is even dramatic in the case of North-East Bulgarian Merino Sheep - from 6457 in 2009 to 3000 in 2014. The impact of Measure 214 has been most positive in the mountainous and semimountainous regions, where the opportunities for intensive agriculture are smaller. However, in the lowlands, the traditional pastoralism could not compete with intensive crop production and other land-use practices (23).

\section{Crop production}

Similarly to the livestock breeding, a severe decline is typical for the Bulgarian crop farming as well. In the post-accession period the production of all major crops, except for the cereals, has dramatically dropped down (Figure 3). The most alarming is the 3 -fold reduction in the vegetable production that has not been halted after the accession of Bulgaria to the EU and the implementation of the RDP (2007-2013). Correspondingly the recent analysis of agricultural sectors eligible for support from RDP ordered by the Bulgarian MAF has outlined this negative tendency during the first programming period 20072013 (25). The same authors point out that unbalanced state support for the cereal crop producers, low competitiveness of the extensive fruit and vegetable farms and the deterioration of the ameliorative systems in the country are among the main factors for the reduction of the national production and increase of the import of fresh fruits and vegetables. Thus, the strong trend for diminishing and irregularity of the yields do not allow Bulgarian fruits and vegetables (and related food produce) to gain popularity and stable markets. Additionally replacement of local varieties with foreign ones and termination of the breeder's rights of many of the indigenous plant varieties aggravated the reduction of Bulgarian varietal diversity. A comparison of the List of the conservation varieties adopted in 2015 and National variety lists for 2000-2003 confirms this unfavourable transition. Out of the 222 varieties included in the List of the Bulgarian conservation varieties, $35 \%$ were part of the Bulgarian official variety lists in the early 2000's (regardlessly in List A, B or the supplements). The Bulgarian famous varieties of cucumbers, sweet peppers, beans, onions, grapes, etc. today constitute a significant part of the national list of the conservation plant varieties (Figure 4).

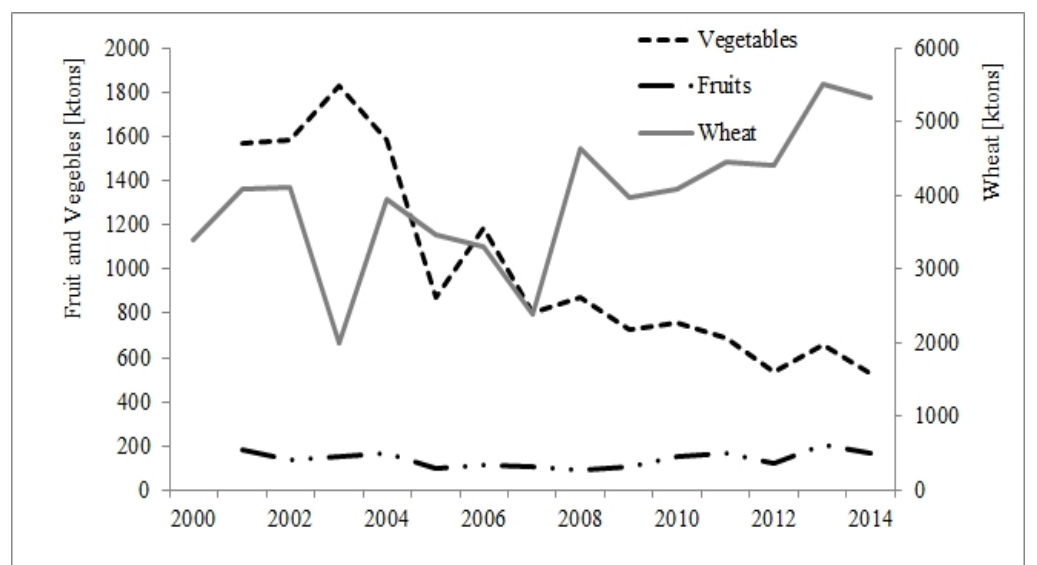

Figure 3. Production of fruits, vegetables and wheat in 2000-2014 (source: MAF Agrostatistics).

Lack of agro-statistical data on variety level for fruits and vegetables in the last years does not allow us to determine the extent to which the cultivation of varieties of Bulgarian origin has declined. However, the increased import and on-going registration of foreign varieties in the Bulgarian variety list indicate quite adverse state of the indigenous plant genetic resources. 
DIMITROVA D., et al.

Following the EC regulation № 1305/2013, the new Bulgarian RDP (2014-2020) includes an agro-ecological measure to support the cultivation of conservation varieties in order to prevent their extinction. This measure could provide additional profit for interested small producers and some compensation to the nonfor-profit variety maintainers (many of them are research institutes or private breeders). The limited production capacity of such producers and restrictions in conservation variety cultivation, however, could not be expected to meet the market demand. Regarding the rich diversity of the Bulgarian local landraces and varieties the adopted list of the conservation varieties does not cover even a small part of the available resources (26). The limitedsuccess of the implementation of the "conservation" directives $(27,28)$ in the Member states should forewarn Bulgarian authorities about the obstacles in setting sustainable basis for effective preservation and promotion of the genetic resources conservation on farm. (29).

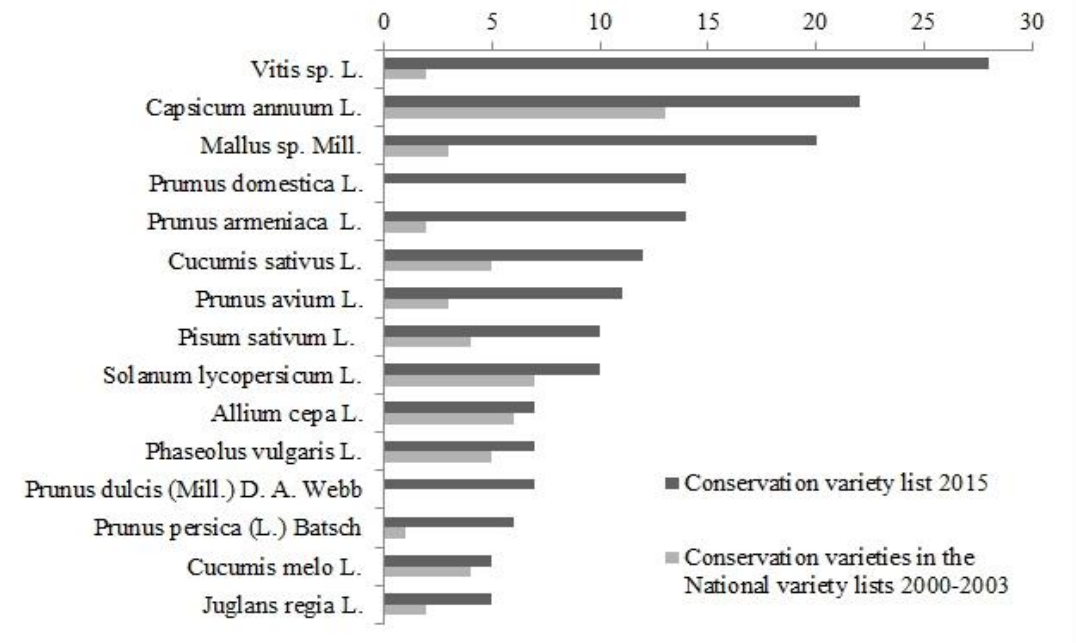

Figure 4. Crop species with five or more varieties included in the Bulgarian national conservation list (source: MAF, Executive agency for variety testing, field inspection and seed control).

\section{ESSEDRA field research outcomes}

The need for specific efforts to maintain the local breeds and varieties of Bulgarian origin is demonstrated by the outcomes from the field research within ESSEDRA project. About 1/2 of the accessed endangered food biodiversity are local plant varieties and animal breeds (Figure 5).
These include popular denominations like Kurtutovska kapiya, several grape varieties, Rhodope short-horn cattle, East Balkan swine, Karakachan sheep, etc. Moreover the decrease of local breeds and varieties impacts production of artisanal traditional products like pestil (Karadjeka plum), Cherni Vit Green cheese (Teteven sheep) and local wines.

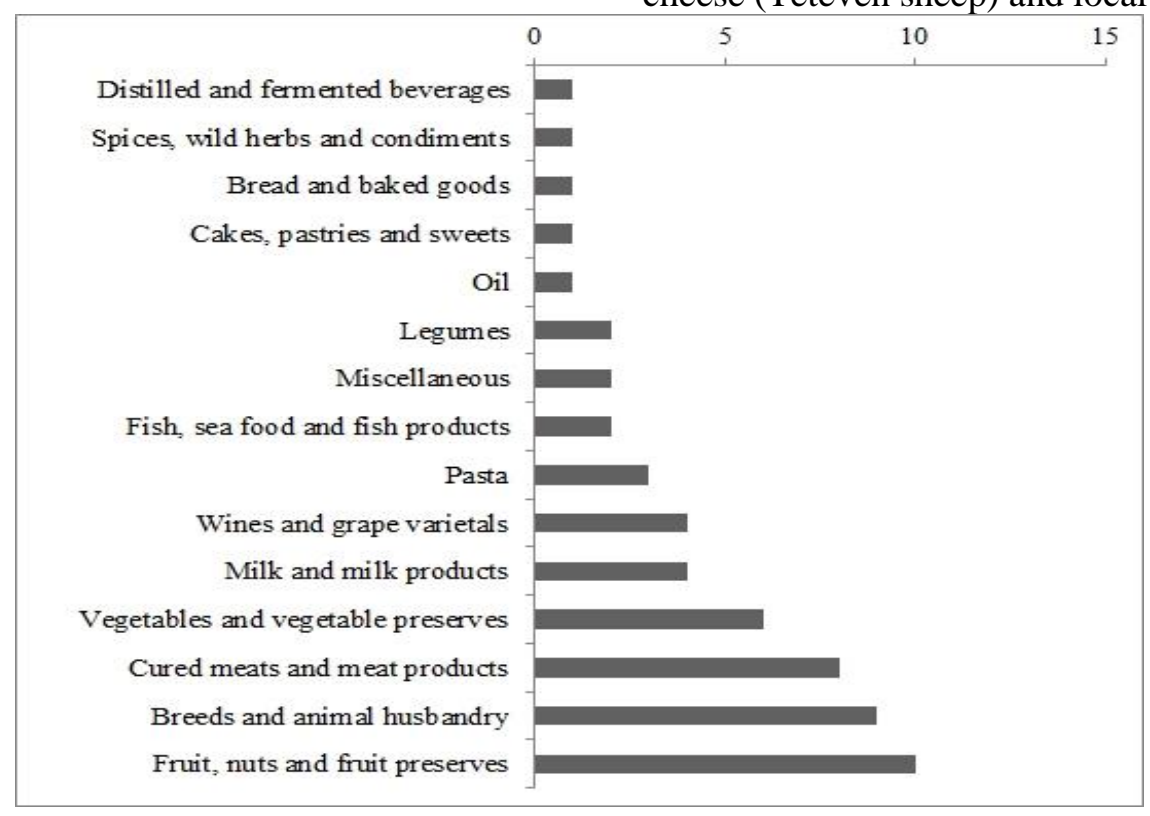

Figure 5. Number of Bulgarian endangered food products, plant varieties and livestock breeds nominated for the Slow Food Ark of Taste. 
The major threats that have been identified in the interviews with producers and farmers are presented on Figure 6. It is obvious that the strongest driver for the decrease of foodrelated biodiversity is the replacement of local autochthonous breeds and varieties with few newer and/or foreign ones. On the one hand the result is expected to be the erosion of the Bulgarian genetic resources. On the other, the monoculture approach makes Bulgarian agriculture susceptible to major losses due to mass diseases and climate change. Furthermore, Bulgaria is losing fast its food sovereignty and becomes dependent of the import of basic food (fruits, vegetables, milk and meat). Abandonment of remote rural areas unfavourable for conventional agriculture and stock breeding is increasing.

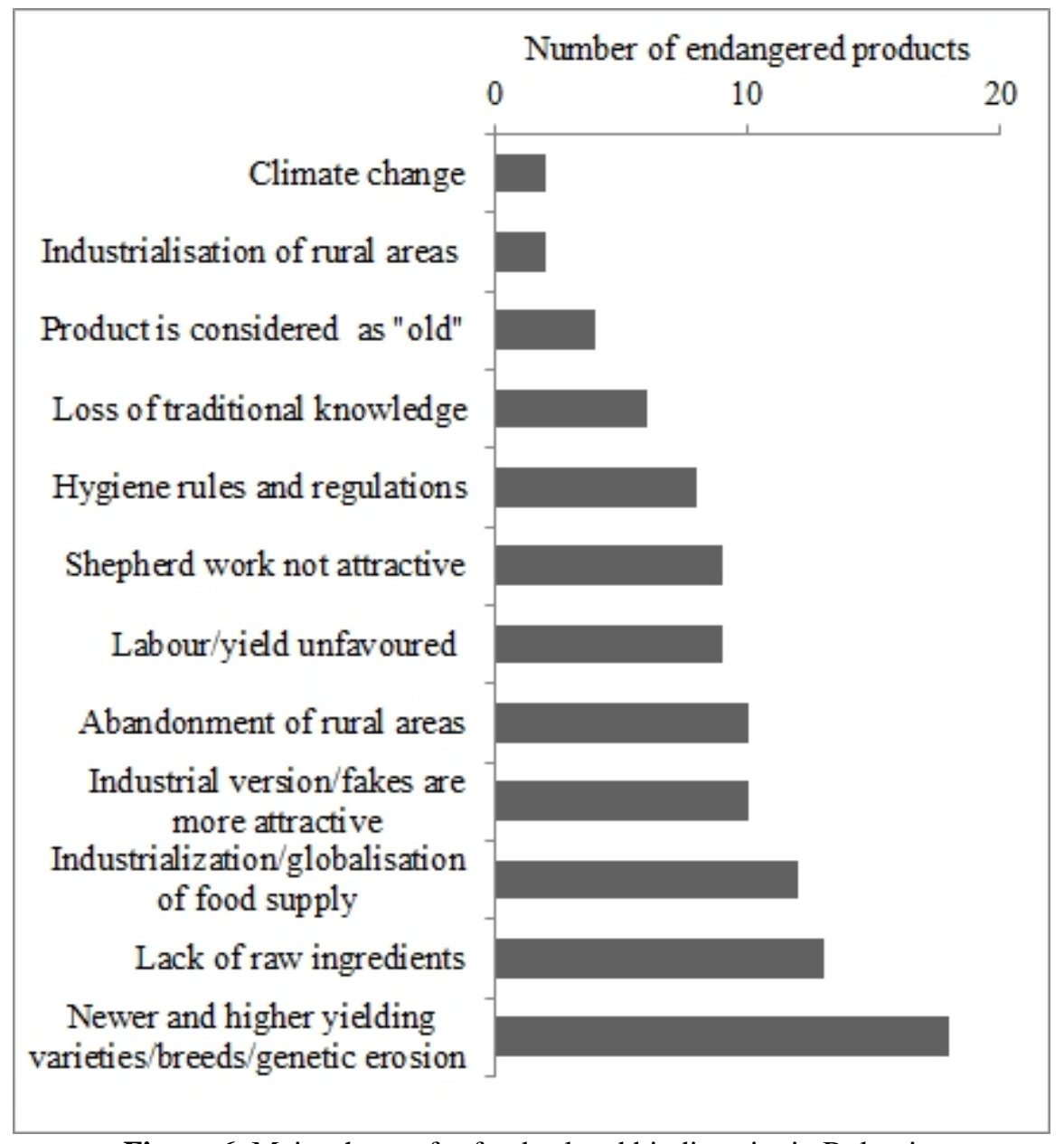

Figure 6. Major threats for food-related biodiversity in Bulgaria.

\section{CONCLUSIONS}

The weak national economy stimulates the consumption of cheap food, most often of low quality. In the same time the demand for high quality food is rising and Bulgarian consumers are looking for sources of food alternatives to large retailers. Thus the consumer demands in the country are in parallel with the European trend where there is a fast growing quest for healthy and gourmet food with annual growth rate of $15-25 \%$ and $5-10 \%$ respectively (30). Additionally Bulgarian consumer is still attached to its memories for home-made food and therefore is prone to marketing tricks that fake "traditional" tastes. This weakens the trust in artisan food and hinders the restoration and establishment of recognisable Bulgarian food specialities. So far only 5 products are registered as 'traditional speciality guaranteed (TSG) and 2 products are registered as protected geographical indications (PGI) (31).

The agro-ecological measures envisaged in the Bulgarian new RDP are expected to stimulate the cultivation of local plant varieties and breeding of autochthonous breeds. The economic feasibility of such initiatives could be improved by proper legal regulation of processing of raw materials on farm and/or in small-scale community-managed enterprises. Currently such possibility is regulated by Ordinance 26 which refers to direct sales of food of animal origin. This should be extended to fruit and vegetable processing as well. 
Today only 464 producers of primary products (332 for honey) and 8 - for processed products ( 7 for milk and 1 for meat) are registered according to Ordinance 26. To increase the number of farmers who avail of this regulation further amendments of the legal act are needed in compliance with the flexibility provisions measures envisaged by DG Sante (32). Flexible implementation of the hygiene package compliant with the economic background of small-scale farmers in Bulgaria could boost local economies creating added value businesses (33). Such approach would also increase the effective utilization of the financial support under RDP (2014-2020) and will help to achieve one of its main goals well balanced development of rural areas. The need for improvement of administrative capacity and procedures are needed in order to increase the number of farmers willing to apply for financial support is promoted also by other authors (23). A state policy specifically oriented to promotion of national genetic resources on a larger scale would ensure national food sovereignty and clear support for the Bulgarian producers seeking recognition through the EU quality schemes.

\section{ACKNOWLEDGMENTS}

This work is funded by ESSEDRA Environmentally Sustainable Socio-Economic Development of Rural Areas (EuropeAid/132438/C/ACT/Multi Contract n. 2012/307-143).

\section{REFERENCES}

1. Donald, P.F., Green, R.E., Heath M.F., Agricultural intensification and the collapse of Europe's farmland bird populations. Proc Royal Soc Biol Sci Series B, 268: 25-32, 2001.

2. Green, R., Cornell, S., Scharlemann J., Balmford A., Farming and the fate of wild nature. Science, 307: 550-555, 2005.

3. Godfray, H., Beddington, J., Crute, I, Haddad, L., Lawrence, D., Muir, J., Toulmin, C., Food security: the Challenge of Feeding 9 Billion People. Science, 327 (5967): 812-818, 2010.

4. Foley, J., DeFries, R., Asner, G., Barford, C., Bonan, G., Carpenter, S., Chapin, F.,Coe, M.,. Daily, G., Gibbs, H., Helkowski, J., Holloway, T., Howard, E., Kucharik, Ch., Monfreda, Ch., Patz, J.,Prentice, I., Ramankutty, N., Snyder, P., Global Consequences of Land Use. Science, 309: 570-574, 2005.

5. World Resources Institute, Millennium Ecosystem Assessment, Ecosystems and Human Well-being: Biodiversity Synthesis. Washington, DC, USA, 2005.
6. Baldock, D., Beaufoy G., Brouwer, F., Godeschalk, F., Farming at the Margins; Abandonment or Redeployment of Agricultural Land in Europe IEEP-LEI, London \& The Hague, 1996.

7. Verhulst, J., Báldi, A., Kleijn, D., Relationship between land-use intensity and species richness and abundance of birds in Hungary Agriculture. Ecosystems \& Environment, 104: 465-473, 2004.

8. Bianchi, F., Mikos, V., Brussaard L., Delbaere, B., Pulleman, M., Opportunities and limitations for functional agrobiodiversity in the European context. Environmental Science \& Policy 27: 223231, 2013.

9. Delbaere, B., Mikos V., Pulleman, M., European Policy Review: Functional agrobiodiversity supporting sustainable agriculture Journal for Nature Conservation 22: 193-194, 2014.

10.Brussaard, L., Caron, P., Campbell, B., Lipper, L., Mainka, S., Rabbinge, R., Babin, D., Pulleman M., Reconciling biodiversity conservation and food security: scientific challenges for a new agriculture. Current Opinion in Environmental Sustainability, 2: 34-42, 2010.

11.Ministry of Agriculture and Food, Republic of Bulgaria, Agrostatistics department, Results and analyses, № 276, 2014.

12.Ministry of Agriculture and Food, Republic of Bulgaria, Agrostatistics department, Annual report on the situation and development of agriculture, 2014.

13.Mladenov, C., and Ilieva, M., The depopulation of the Bulgarian villages. Bulletin of Geography. Socio-economic Series, 17: 99-107, 2012.

14. Ministry of Agriculture and Food, Republic of Bulgaria, Executive agency for variety testing, field inspection and seed control, Bulgarian official variety list, Sofia, 2000.

15.Ministry of Agriculture and Food, Republic of Bulgaria, Executive agency for variety testing, field inspection and seed control, Bulgarian official variety list, Sofia, 2001.

16. Ministry of Agriculture and Food, Republic of Bulgaria, Executive agency for variety testing, field inspection and seed control, Bulgarian official variety list, Sofia, 2002003.

17.National Statistical Institute, 129 years Bulgarian statistic. NSI, Sofia, 2009

18. National Statistical Institute of Republic of Bulgaria, Statistical yearbook 2014. NSI, Sofia, 2010.

19.National Statistical Institute of Republic of Bulgaria Statistical yearbook 2015. NSI, Sofia, 2015. 
20.Ministry of Agriculture and Food, Agrostatistic department, Red meat slaughterhouses activity and meat production in Bulgaria during 2014, 2015.

21.Ministry of Agriculture and Food, Executive Agency for Selection and Reproduction in Animal Breeding (EASRAB), Information systems EFABIS, http://www.efabis-bg.iasrj.eu, 2014

22.Nikolov, V. (ed.), Livestock Breeds in the Republic of Bulgaria, (2011). EASRAB, Sofia, 2011.

23.Nikolov, V., Review of the specific measures for support of the autochthonous breeds in Bulgaria. Journal of Central European agriculture, 16(2): 38 - 46, 2015

24. State Gazette, Ordinance amending and supplementing Ordinance № 11 of 2009 on the terms and conditions for the implementation of measure 214 "Agrienvironment payments" from the Program for Rural Development 2007 - 2013, 2013.

25.Nikolov, D., Yovchevska, P., AtanasovaChopeva, M., Koteva, N., Mladenova, M., Analysis of the supported production sectors. Institute of Agricultural Economics, Agricultural Academy, Sofia, Bulgaria, 2014.

26.Krasteva, L., Stoilova, T., Varbanova K., Neykov, St., Bulgarian Landrace Inventory - Significance and Use. In: Veteläinen, M., Negri, V., Maxted, N. (eds), European landraces on-farm conservation, management and use. Bioversity Technical Bulletin No. 15 Bioversity International, Rome, Italy. 2009
27.EC, Council Directive 2008/62/EC, Commission of the European Union, Brussels, Belgium, 2008.

28.EC, Council Directive 2009/145/EC, Commission of the European Union, Brussels, Belgium, 2009

29.Kastler, G. and Moÿ, A-C., The European Union directive on conservation varieties and its incompatibility with on-farm management of plant genetic resources. In: De Boef, W., Subedi, A., Peroni, N., Thijssen, M., O'Keeffe, E. (eds), Biodiversity Management. Promoting resilience and the conservation of plant genetic resources, Routledge, New York, NY, pp. 332-338, 2013.

30.FAO, Promotion of traditional regional agricultural and food products: a further step towards sustainable development. 26th Regional Conference for Europe and Central Asia (ERC), Innsbruck, Austria, 2627 June 2008. ftp://ftp.fao.org/docrep/fao/meeting/013/K2 473E.pdf, 2008.

31.EC, DOOR Database. http://ec.europa.eu/agriculture/quality/door/ list.html, 2015.

32.EC, Food Hygiene - Guidance documents. http://ec.europa.eu/food/food/biosafety/hygi enelegislation/guide_en.htm, 2015.

33.TRUEFOOD, Guideline on effective knowledge and technology transfer activities to SMEs in the food sector with particular focus on traditional food manufacturers, 2009. 